\title{
Manufacture and Sensor's Characterization for Optimizing the Manufacture of Resistance Sensors Based on Honeycomb and Honey Market
}

\author{
Ayu Sakila Arum*, Dyah Imas Cholidina**, Frida Agung Rakhmadi*** \\ Physics Department, Faculty of Science and Technology, UIN Sunan Kalijaga \\ Email: ayutmlnsn@gmail.com*; dyhcholidina@gmail.com**; frida.rakhmadi@uin-suka.ac.id***
}

\begin{abstract}
This research aims to identify resistance sensors based on honeycomb and honey market. It was conducted in three stages, namely sensor design, sensor manufacturing and sensor characterization. The sensor scheme has been made by software fritzing. The tools used in the sensor manufacture are PCB sensors, resistors and copper wire. The tools used in sensor characterization are provided by power supply, CRO and samples. Sensor testing is done by varied the sample into 6 variations accurately $5 \mathrm{ml}, 10 \mathrm{ml}, 15 \mathrm{ml}, 20 \mathrm{ml}, 25 \mathrm{ml}$, and $30 \mathrm{ml}$. Data generated from the sensor in the form of voltage. Repetition on each volume variation was 10 times. Then, It was be processed by calculating the compatibility and the average of the voltage produced along with its uncertainty. The results showed the average of the voltage generated with the uncertainty at $5 \mathrm{ml}$ volume $(9,052 \pm 0,001) \mathrm{V}$ and $(8,682 \pm 0.017) \mathrm{V}$, for volume of $10 \mathrm{ml}(9,040 \pm 0.025) \mathrm{V}$ and $(8,531 \pm 0.050) \mathrm{V}$, for volume of $15 \mathrm{ml}(8,947 \pm 0.073) \mathrm{V}$ and $(8.230 \pm 0.018) \mathrm{V}$, for volume of $20 \mathrm{ml}(8.999 \pm 0.073) \mathrm{V}$ and $(8,209 \pm 0.007) \mathrm{V}$, for volume of $25 \mathrm{ml}$ $(8.967 \pm 0.080) \mathrm{V}$ and $(7.689 \pm 0.048) \mathrm{V}$ and for volume of $30 \mathrm{ml}(8,925 \pm 0,040) \mathrm{V}$ and $(8,284 \pm 0,018) \mathrm{V}$. Repeatibility has produced on this sensor was obtained from two samples, honeycomb by $90.919 \%$ and honey market by $94.432 \%$. Based on the results obtained from the calculation, it can be determined that the transfer function was $\mathrm{V}=9.06853 \mathrm{x}-0.0045828571$ and $\mathrm{V}=8.72453 \mathrm{x}-0.0259257143$. The linear correlation coefficient obtained by $95.9 \%$. This research will be used for optimizing the manufacture of resistance sensors with good characteristics.
\end{abstract}

Keywords: characterization, resistance sensor, honeycomb, honey market

\section{INTRODUCTION}

In the Quran:

$$
\begin{aligned}
& \text { “... from all the fruits and follow the ways of your Lord } \\
& \text { laid down [for you]." There emerges from their bellies a } \\
& \text { drink, varying in colors, in which there is healing for } \\
& \text { people. Indeed in that is a sign for a people who give } \\
& \text { thought.” (QS An-Nahl : 69) }
\end{aligned}
$$

From the verse explained that honey is very beneficial for health and treatment of all kinds of diseases.

Honey has been known as one of the natural foods or drinks that have an important role in life and health. Honey is a natural product produced by bees for consumption, because it contains essential nutrients. Honey isnt only a sweetener, or food flavoring, but is also often used for medicine and beauty. Honey can be used to relieve fatigue, and also can be used to smooth the skin, and hair growth.

Honey produced by honey bees comes from flowers. Honey has a different color, scent and taste, depending on the type of plant that grows around honey beekeeping (Sarwono, 2001). For example mango honey (slightly sour taste), cucumber flower honey (it tastes very sweet), kapok honey / kapok (tastes sweeter, more legit and somewhat savory), longan honey (sweet taste, more legit and sharper scent). Also known as rambutan honey, kaliandra honey and rubber honey. (Suranto, 2004)

Good honey must completed the conditions set by the Indonesian Industrial Standards (ISS) in 1977 and 1985 (Suranto, 2004). Levels in accordance with ISS standards may only be found in pure honey, that is honey that hasnt been mixed with other. In the domestic market, guarantees of the authenticity and quality of honey still do not exist, therefore suspicion of the falsehood of honey is always there (Suranto, 2004; Sujatmaka, 1988). Therefore, this study was conducted to determine differences in honey samples seen from the value of resistance.

\section{MATERIALS AND METHODS}

This research was conducted in three stages, the design of resistance sensors, the manufacture of resistance sensors and the characterization of resistance sensors. The three stages can be explained as follows.

The first stage is the designed of resistance sensors that have the aim to optimize the manufacture of resistance sensors. This stage was made to produce a resistance sensor design. The design of this resistance 
sensors is made with a software application called fritzing.

The second stage was the manufactured of resistance sensors. This stage is the process of made resistance sensors. This stage makes the resistance sensor that was previously designed. The tools that need to be used at this stage are PCB, 2 resistors $(100 \Omega)$ and copper wire.

The third stage was resistance sensors characterization. This stage has the aim to testing the characteristics of the resistance sensors that has been made. This stage will be produce the results of resistance sensors testing and can understand the characteristics of the resistance sensors that has been made. The tools and materials to be used in this stage are power supply, CRO, measuring cup, stirrer and samples. Sensor characterization includes average voltage along with uncertainty, repeatability, and linear correlation coefficient. Power supply as a voltage source and CRO as a sensor output.

Testing of samples were conducted using 2 honey samples, honeycomb and honey market. Samples are varied in up to 6 volume variations $5 \mathrm{ml}, 10 \mathrm{ml}, 15 \mathrm{ml}$, $20 \mathrm{ml}, 25 \mathrm{ml}$ and $30 \mathrm{ml}$. The volume of water used in this research was $40 \mathrm{ml}$. Retrieval of data is taken with a resistance sensors that has been made by dipping the copper wire into the samples to the bottom of measuring cup which then produces an output in the form of a voltage on the CRO. Repetition on each volume variation was 10 times. After the data is generated, a data analysis is performed to characterize the resistance sensors. To get the average value used equation (1)

$\bar{V}=\frac{\sum V i}{N}$

Where $\mathrm{V}$ is the average resistance value and $\mathrm{N}$ is the number of measurements. After obtaining the average value of resistance continued by determining the uncertainty value of the experiment used equation (2) (Morris, 2014)

$\Delta V=\frac{1}{N} \sqrt{\frac{N \sum V i^{2}-\left(\sum V i\right)^{2}}{N-1}}$

Thus to get the repeatability value the following equation is used:

$$
\delta=\frac{\Delta}{F S} \cdot 100 \%
$$

Repeatability $=100 \%-\delta$

The value of "a" represents zero offset (ie slip), i.e. the output signal when the input signal is zero can be used equation

$a=\frac{\sum V i \sum X i^{2}-\sum X i \sum X i . V i}{n \sum X i^{2}-\left(\sum X i\right)^{2}}$
The value od "b" represents the slope (the slope of a straight line), which was often also called sensitivity and resolution can be used equations

$b=\frac{n \sum X i . V i-\sum X i \sum V i}{n \sum X i^{2}-\left(\sum X i\right)^{2}}$

Based on the results obtained from these calculations, the resistance sensor transfer function can be determined

$\mathrm{V}=\mathrm{a}+\mathrm{bx}$

From the data generated, the sensor can be trusted by calculating the linear correlation coefficient of equation (4)

$$
r=\frac{n \sum I i V i-\sum I i \sum V i}{\sqrt{\left(n \sum I i^{2}-\left(\sum I i\right)^{2}\right)\left(n \sum V i^{2}-\left(\sum V i\right)^{2}\right)}}
$$

$\%=r \times 100 \%$

Based on the results of data from the graph of volume (ml) Vs. Voltage (V), Resistance sensors characteristics including static or dynamic characteristics.

\section{RESULTS AND DISCUSSION}

The results of the sensor design are made with fritzing software. The results of the design and manufacturing results can be showed in Figure 1.
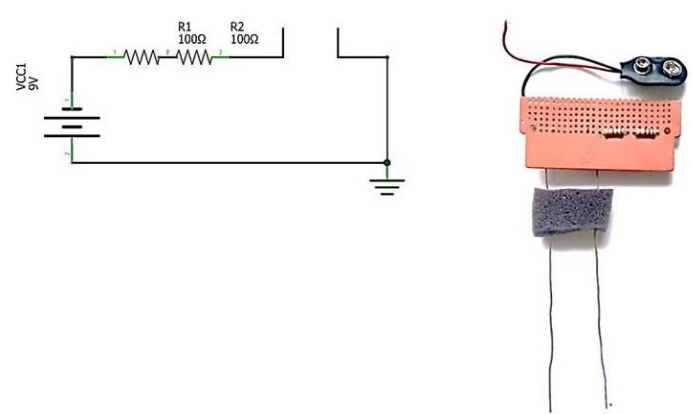

Figure 1. Results of Design and Manufacture of Resistance Sensors.

This resistance sensors used a voltage of $9 \mathrm{~V}$. The resistors used are as many as two resistors at $100 \Omega$. On the sensor there are two copper wires $2 \mathrm{~cm}$ apart. The wire will be dipped in the sample to the bottom of the measuring cup which will then read the resistance sensors. The sample in this research serves as an object in characterizing the sensors that have been made. The results of data analysis that have been carried out on two different samples produced an average voltage on the sample with variations in volume and its uncertainty can be showed by 
Table 1. Results of Resistance Sensor Characterization in Honey comb samples.

\begin{tabular}{ll}
\hline Volume $(\mathbf{m l})$ & Voltage $(\mathbf{V})$ \\
\hline 5 & $9,052 \pm 0,001$ \\
10 & $9,040 \pm 0,025$ \\
15 & $8,947 \pm 0,073$ \\
20 & $8,999 \pm 0,073$ \\
25 & $8,967 \pm 0,080$ \\
30 & $8,925 \pm 0,040$ \\
\hline
\end{tabular}

Table 2. Results of Resistance Sensor Characterization in Honey market samples.

\begin{tabular}{ll}
\hline Volume $(\mathbf{m l})$ & Voltage $(\mathbf{V})$ \\
\hline 5 & $8,682 \pm 0,017$ \\
10 & $8,531 \pm 0,050$ \\
15 & $8,230 \pm 0,018$ \\
20 & $8,209 \pm 0,007$ \\
25 & $7,689 \pm 0,048$ \\
30 & $8,284 \pm 0,018$ \\
\hline
\end{tabular}

The repeatability was obtained by $90.919 \%$ and $94.432 \%$. The results obtained from these calculations can be determined resistance sensors by transfer function was $\mathrm{V}=9.06853 \mathrm{x}-0.0045828571$ and $\mathrm{V}=8.72453 \mathrm{x}$ 0.0259257143 . The percentage of the linear correlation coefficient produced by $95.9 \%$ and the resistance sensors made was trusted. Based on the results of data from the graph of volume (ml) Vs. Voltage $(\mathrm{V})$, the characteristics of this resistance sensors did not include by dynamic characteristics because it wasn't be on the time so the characteristics of the resistance sensors was static characteristics.

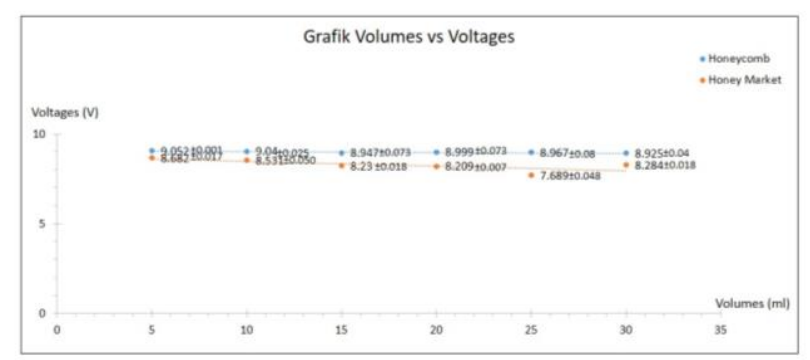

Figure 2. The voltage difference between honeycomb and honey market.
Figure 2. showed the voltage in honeycomb is higher than the voltage in honey market. Higher volumes indicate a decreased voltage values in honeycomb but different voltage values at a higher volume in honey market. These results illustrated the characterization of honeycomb with honey market including biological measurements. With more different method of characterization will optimize the manufacture of honey detection systems. The results of this sensor characterization showed that in the future resistancebased detection devices can be developed to detect differences of honey.

\section{CONCLUSION}

Resistance sensors based on honeycomb and honey market was conducted in three stages, namely sensor design, sensor manufacturing and sensor characterization. The sensor scheme has been made by software fritzing. The results of this research illustrated the characterization of honeycomb with honey market including biological measurements. The results of this sensor characterization showed that in the future resistance-based detection devices can be developed to detect differences of honey.

\section{REFERENCES}

Al-Qur'an

Morris, Alan S. Langari, Reza. 1948. Measurement and Instrumentation Theory and Application, USA.

Sujatmaka, 1988. Menghasilkan Madu Berkualitas Tinggi, Trubus. Jakarta.

Suranto, A., 2004. Khasiat dan Manfaat Madu Herbal, Agromedia Pustaka, Tangerang. 
THIS PAGE INTENTIONALLY LEFT BLANK 